\title{
LOS “PORTEROS” Y EL CUIDADO DE LOS EDIFICIOS ESCOLARES. UNA MIRADA ETNOGRÁFICA SOBRE LOS SUJETOS Y LAS POLÍTICAS EDUCATIVAS
}

\author{
Diana Milstein (Universidad Nacional del Comahue)* \\ diana_mils@yahoo.com.ar \\ Silvina Fernández (Universidad Nacional del Comahue)* \\ silfernandez17@hotmail.com
}

Recibido: 29/07/2011 Aceptado: 26/10/2011

\section{Resumen}

Los distintos actores políticos y los lugares de lo político en la escuela han sido habitualmente analizados desde definiciones que reconocen su peso centrado en los ámbitos jurídico-políticos del Estado en sus vínculos con el resto de la vida social. A través de ello ha quedado velada la presencia de otros actores, espacios y prácticas que resultan fundamentales para comprender procesos de confrontación y negociación relativos a la aplicación de políticas educativas.

El interés por comprender manifestaciones recurrentes que tienden a alterar y desarticular los carriles por los que transita la vida cotidiana de las escuelas primarias en la ciudad de Neuquén, nos confrontó con la necesidad de describir situaciones que nos llevaron a considerar la manera particular en la que se vinculan porteras/ os a través de lo cotidiano con las políticas educativas nacionales y provinciales. La pugna por el control que ejercían los/as porteros/as a través del aspecto edilicio ante a una dirección debilitada, ponía sobre el tapete su protagonismo en la toma de las decisiones, interviniendo en la política educativa y su materialización en el cotidiano escolar. Esto nos condujo a considerar que para comprender las políticas edilicias en el sector educación, era imprescindible poner el foco en los sujetos y colectivos que intervienen y en las relaciones sociales implicadas en la implementación de esas políticas y así evitar análisis inconducentes de políticas en términos dicotómicos: protagonismo o ausencia del Estado.

* Doctora en Antropología Social por la Universidad de Brasilia.

* Profesora en Ciencias de la Educación por la Universidad Nacional del Comahue 


\section{Palabras claves}

Escuela Primaria - Actores - Política - Vida Cotidiana.

\section{Abstract}

The different political actors and political sites in school have usually been analyzed from definitions that focus their importance on the legal-political State in its ties with the rest of social life. Through it has been concealed the presence of other actors, spaces and practices that are fundamental to understanding processes of confrontation and negotiation on the implementation of educational policies.

The interest in understanding recurrent events that tend to disrupt and dismantle the ways through which passes the daily life of primary schools in the city of Neuquén, faced us with the need to describe situations that led us to consider the particular way in which linked gatekeepers through daily life with the national and provincial education policies. The fact of seeing them actively involved in the circuit of their implementation, mediation between schools and authorities, put on the table its role in making decisions, taking part in educational policy and its realization in everyday school life. This led us considering that to understand building policies in education sector, it was imperative to focus on individuals, groups and social relationships involved in the implementation of these policies to avoid irrelevant policy analysis in dichotomous terms : ownership or absence of the State.

\section{Key words}

Primary School - Actors - Politics - Everyday life.

\section{Porteros y porteras en la escena política escolar}

Los distintos actores políticos y los lugares de lo político en la escuela han sido habitualmente mirados y analizados desde definiciones que reconocen el lugar y el peso de lo político fundamentalmente en los ámbitos formales del Estado, en sus vínculos con el resto de la vida social. Desde esta perspectiva, se ha podido identificar y analizar algunos de los efectos del poder político del Estado en la conformación de las relaciones sociales de las instituciones escolares. Pero la presencia de otros actores, espacios y prácticas ha quedado velada, a pesar de resultar fundamental para comprender procesos relativos a la aplicación de políticas educativas diseñadas desde el Estado nacional y provincial.

Un ejemplo de esta presencia velada son algunas de las prácticas y relaciones sociales vinculadas a la construcción y mantenimiento, cuidado, limpieza, decoración, etc. de los edificios donde funcionan las escuelas públicas. Funcionarios y funcionarias, docentes, empleados y empleadas escolares no docentes, familiares, alumnos y alumnas, periodistas, entre otros, consideran el tema edilicio escolar dentro de lo que aquí denominamos el ámbito jurídicopolítico del Estado. Asimismo, lo vinculado al mantenimiento, cuidado, limpieza 
y decoración de los edificios es visto por la mayoría como pertenecientes a un ámbito percibido como ajeno a la política, difícil de nombrar por su vaguedad, que abarca actitudes, voluntades, temperamentos, deseos, gustos, "modos culturales" de quienes comparten la vida cotidiana de las escuelas. Este es el ámbito que nos interesó pensar antropológicamente en términos políticos. Advertimos así que todo aquello que sucedía dentro de él, se percibía como no político porque no estaba reducido a las instancias formales de poder y a las instituciones legales del poder político del Estado. Sin embargo, los conflictos públicos que se desataron, la confrontación entre grupos y sujetos dentro y fuera de la escuela y los cuestionamientos -siempre vinculados a las formas de ejercicio del poder- pusieron en evidencia que estábamos ante fenómenos políticos.

El conjunto de acciones, comportamientos y discursos que registramos durante la primera semana en la que iniciamos nuestro trabajo de campo -coincidente con el inicio del período lectivo en 2010- en la escuela estatal primaria 1 de la ciudad de Neuquén -como la nombraremos en este artículo- está, en gran parte, vinculado a conflictos en torno al cuidado del edificio, a su limpieza y al uso de sus instalaciones. Estos conflictos se reiteraron de manera continua durante todo el año 2010 y se nos presentaron de manera similar durante el inicio de este año lectivo, 2011, produciendo desde suspensiones de días y semanas de clases hasta discusiones, disputas, alteraciones, desarticulaciones en la vida cotidiana de la escuela.

Funcionarios del área educativa de la provincia de Neuquén han enfatizado en sus discursos mediáticos el mejoramiento y reposición de la infraestructura arquitectónica escolar, pero en los hechos, el deterioro de los edificios ha conducido a que una alta proporción de escuelas resulten lugares inadecuados para dar clases de manera continuada. En los comienzos del ciclo lectivo de este año -marzo de 2011- la directora de la escuela nos comentaba que tres semanas antes, todo el personal directivo de las escuelas había sido convocado para asistir a un curso de capacitación en higiene y seguridad organizado por el Consejo Escolar de la Provincia y Defensa Civil. Con un gesto risueño nos dijo:

"no les voy a contar todo lo que dijeron, la cantidad de normas que teníamos que saber porque la verdad es que si se decidiera cumplir con la mitad de esta normativa tendrian que cerrar casi todas las escuelas de la provincia" (Registro de campo: Directora escuela 1, 2/3/2011).

Las situaciones conflictivas que suscitan los problemas edilicios forman parte de una de las situaciones de alteración más generalizada en el funcionamiento de las escuelas, producida por una combinación de factores. Sin embargo, detenerse en los problemas concretos vinculados a la cuestión edilicia, nos permite poner en escena el protagonismo de porteros y porteras 
(el cargo que ocupan estos trabajadores en las escuelas primarias de la provincia de Neuquén es de auxiliares de servicio, nosotras utilizaremos porteros y porteras porque así se nombran y son nombrados en general), quienes no son reconocidos como protagonistas en el circuito de implementación de las políticas educativas. Asimismo, da lugar a considerar la combinación de fuerzas que pugnan en la dialéctica por implementar, redefinir y resistir las políticas educativas en la vida cotidiana escolar.

No es una novedad incluir a los porteros y las porteras como trabajadores vinculados directamente al cuidado de los edificios escolares. La originalidad en nuestro planteo radica en considerar que en la actualidad ese trabajo de mantener, cuidar y limpiar, define aspectos claves de las relaciones políticas que se producen al interior de la vida cotidiana de las escuelas; y que, a su vez, tiene repercusión en lo que consideramos nuevas formas en que el Estado provincial interviene en la vida de las escuelas a través de sus políticas educativas edilicias.

\section{Un "plan con tomas" y la escuela del Oeste}

Durante los últimos veinte años la ciudad de Neuquén, capital de la provincia homónima, ubicada al norte de la Patagonia argentina, ha experimentado un fuerte crecimiento poblacional que incluye un importante movimiento inmigratorio y migratorio, proveniente de países vecinos, diferentes provincias del país y ciudades del interior de la misma; respectivamente. Si bien este proceso es característico del conjunto de la ciudad neuquina, la mayor concentración del crecimiento se ha localizado en "el oeste", como habitualmente lo llaman los/ as neuquinos/as. Dos aspectos nos llevaron a centrar nuestra atención sobre esta parte de la ciudad: la alta concentración de grupos empobrecidos ligados al trabajo precario, temporario e informal, y la presencia de una geografía barrial que combina planes de vivienda y las denominadas "tomas".

El sector "Oeste" en su porción norte - donde está emplazada la escuela 1- comenzó a poblarse a partir de los primeros años de la década de los '90 en los cuales el gobierno provincial creó planes de viviendas. Simultáneamente muchos de los trabajadores de las empresas constructoras que eran traídos por éstas desde el interior neuquino y de otras provincias -principalmente del norte argentino- optaron por ocupar terrenos en la misma zona para radicarse en la capital. Las viviendas del plan tuvieron estructuras edilicias diferentes de acuerdo a la empresa que la construía: casas de un solo piso, monoblocks, en ambos casos con dimensiones y materiales diversos. A la vez, los terrenos ocupados por los trabajadores recién llegados eran edificados "por esfuerzo familiar" tomando cada casa configuraciones muy diferentes. Una maestra de la escuela estudiada y que vive en una de las casas del plan de viviendas definió la geografía barrial como "un plan con tomas". Mientras relataba la historia del lugar donde vive desde hace diecinueve años, aclaró, con cierta molestia, que 
al poco tiempo de entregada su vivienda, un domingo se levantó para caminar hacia las bardas con su hija y se encontró con la novedad de una "toma" de terrenos lindante con su vivienda. "Eran todas casitas blancas de madera o sea, blanca porque era madera nueva ¿no? (...) El sábado no había nada... eso se montó de un día para el otro. El sábado a la noche se pusieron todas esas casitas (...) evidentemente han venido camiones con la madera y gente que las puso". Continuó su relato manifestando que el crecimiento que implicó el asentamiento de las tomas "los chupó" como barrio: "tanto nos chupó que en el verano nos quedamos sin agua (...) porque se pinchan las mangueras o se le da prioridad a esta zona [de tomas] iTodo nos chupó! (...) Son conexiones que no es lo que corresponde frente a una planificación". En contraposición con esta última frase explicó que una "toma" surge cuando "hay un espacio vacío, vengo y lo tomo y pongo una casilla, o levanto con madera, o con lo que sea, una pieza y me pongo a vivir ahí". Quien realizó este relato sobre el lugar es una de las pocas maestras de la escuela que vive en la zona en la que residen la mayor parte de los niños y las niñas que van a la escuela, así como la mayoría de los porteros y las porteras.

La escuela está situada dentro del predio de este mismo plan. Comenzó a funcionar hace 16 años por pedido de los pobladores quienes, tras continuos reclamos, lograron que el Consejo Provincial de Educación designara ese espacio para la escuela solicitada y pusiera allí una "escuela de emergencia", tal como fue definida por la misma maestra. "No es una escuela que se construye de materiales, se trae de una de las empresas (...) comedores de esos para la gente que trabaja, (...) gamelas". Una vez instalada la escuela, pasados unos años y ante las demandas de los vecinos, se instaló en el mismo predio un jardín de infantes y otra escuela. Para esta última destinaron un obrador en el que funcionó durante un tiempo hasta ser trasladada a un predio con edificio propio a unas diez cuadras de la escuela 1. Hacia finales de los '90 utilizaron ese mismo obrador y el mismo terreno para inaugurar la escuela primaria 2, que actualmente linda con la escuela primaria 1. Años después, la escuela 2 logro tener un edificio de ladrillos y mampostería.

La escuela 1 continúa hasta la fecha funcionando en las gamelas. Este tipo de construcción prefabricada se compone de paredes y cielorrasos de durlock montados sobre piso de material, elementos que obviamente no soportan el uso que se les está dando desde hace tantos años. Sus aberturas, tanques de agua, cañerías, instalación eléctrica, artefactos de baño y cocina, si bien se han ido arreglando o "emparchando", en los términos que habitualmente utilizan quienes allí trabajan, muestran un nivel de deterioro muy notable. Este serio problema de infraestructura y recursos materiales de funcionamiento no es un caso singular de una escuela, sino de la mayor parte de las que están en los sectores norte y sur del Oeste de la ciudad de Neuquén. En todo caso, la singularidad de la escuela 1 reside en haber mantenido las mismas 
condiciones de precariedad en la infraestructura desde sus comienzos, hace dieciséis años. Un ejemplo que ilustra estas problemáticas edilicias es el lugar de la bandera de ceremonia durante los actos escolares. Antes de comenzar cualquier acto, un portero saca una de las placas de durlock del cielorraso para dejar un agujero y así se logra la altura necesaria para que la bandera pueda sostenerse de manera vertical durante la entonación del himno nacional argentino. Si pensamos en la solemnidad que en las escuelas primarias se le otorga a la presencia de la bandera, los abanderados y escoltas y el protocolo que acompaña esta presencia, podremos imaginar la amplitud simbólica implicada en los problemas edilicios.

La estructura del edificio de la escuela 1 se corresponde con la figura de un rectángulo, el espacio más grande es una galería al que dan la mayoría de las aulas de la escuela, las puertas de los baños, la cocina, el laboratorio, que se utiliza como patio interno.

La foto A muestra la galería que, como se puede apreciar, es un pasillo ancho (utilizado como patio cubierto) al que dan las puertas de las 10 aulas, algunas de ellas pueden verse a la derecha de la foto. Frente a las aulas, a mano izquierda, se encuentran los baños de varones, de mujeres y el de los/as docentes. Aproximadamente a mitad de pasillo hay una puerta de dos alas que lo comunica con un sector del patio externo. Unos pasos después de esta puerta se encuentra la cocina y al lado, el baño que usan los porteros y las porteras. Esta fotografía fue sacada desde arriba de los escalones que dividen la parte descripta con el sector en el que se encuentran la dirección y secretaría, la biblioteca y la sala de maestros, parte de las cuales pueden verse en la foto B. En ella se ve el único sector construido con ladrillos y mampostería y siguiendo en dirección a las ventanas del fondo se encuentra la sala de computación. La puerta que se ve a la izquierda de la dirección es la que permite el acceso a la biblioteca; hacia la derecha se encuentra también el portón de ingreso/egreso a la escuela.

El patio de la escuela 1 linda con el patio de la escuela 2, ambos están divididos por un paredón corto con rejas y una puerta que, en general, permanece cerrada con candado. Como puede ser apreciado en la foto C, el mismo, tiene una porción de piso de cemento y otra de tierra, aros de básquet y arcos de fútbol. Continúa hacia la parte trasera, desde la cual puede verse el jardín de infantes que se encuentra en la misma manzana.

La escuela recibe alrededor de 500 alumnos entre los dos turnos: mañana y tarde. El personal que allí trabaja está conformado por el equipo directivo con una directora y una vicedirectora, existe un cargo de secretaria, aproximadamente 25 docentes y 10 auxiliares de servicio, 5 por cada turno, de los cuales dos porteras, además, son las encargadas de la biblioteca de la escuela. Durante el turno noche funciona en el mismo edificio una escuela primaria de adultos, y hasta el año pasado también se utilizaba el patio luego de las 17 o 18 horas para que niños/as del barrio realicen actividades físicas organizadas 
por el centro deportivo municipal, el cual no cuenta con edificio propio. Todas las actividades que se desarrollan luego de las 17:30 solo comparten el edificio con la escuela 1.

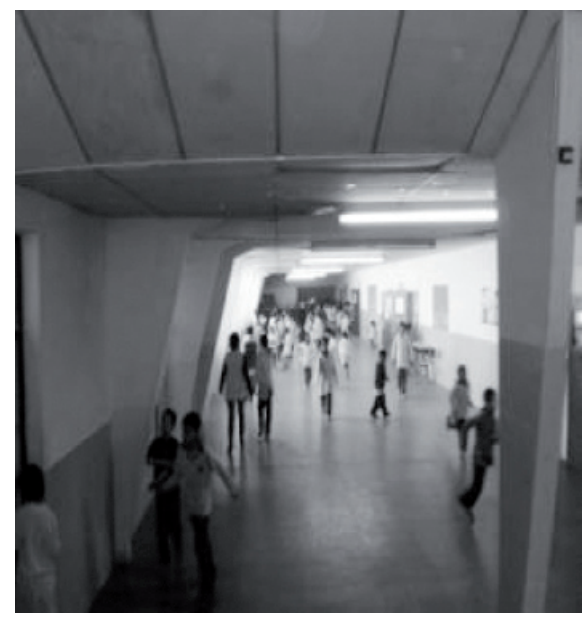

Foto A. Pasillo, patio interno Escuela 1

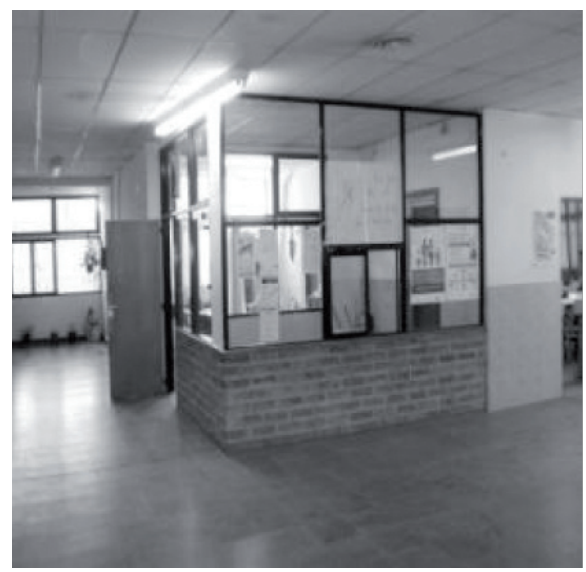

Foto B. Dirección y secretaria Escuela 1 


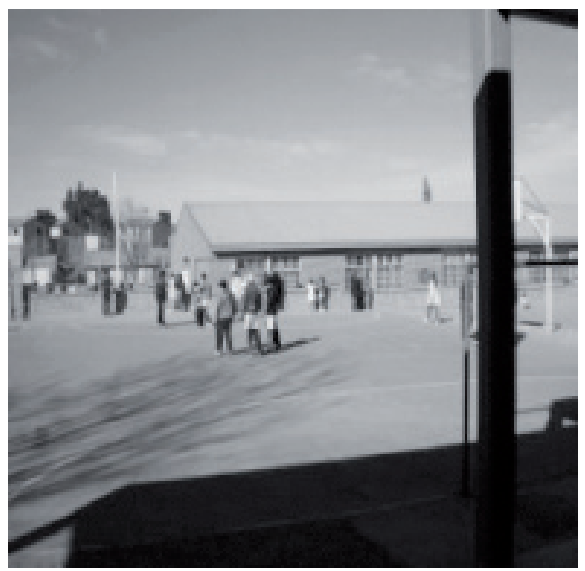

Foto C. Patio de la Escuela 1 y parte trasera y patio

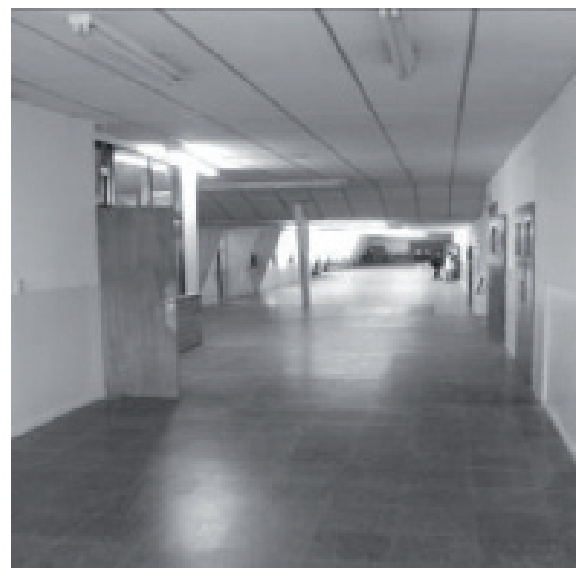

Foto D. Vista total del patio interno Escuela 1 de la Escuela 2

La directora de esta escuela asumió su cargo a mediados del año 2009. No se había trabajado previamente en esta institución, aunque llevaba ya muchos años trabajando en escuelas primarias de la provincia. Primero como maestra y luego como directora. Su cargo anterior había sido desempeñado en Plottier, ciudad cercana a la capital neuquina, en donde reside. En alguna conversación definió su estar en la escuela como "un paso", ya que está próxima a jubilarse. La vicedirectora, en cambio, es una maestra con antigüedad en la escuela. 
Entre los/as docentes, algunos llevan varios años trabajando en la institución y la mayoría ha trabajado siempre en escuelas de la zona.

Poco tiempo después de iniciado nuestro trabajo de campo percibimos que en la escuela se vivía un cierto malestar que, en parte, estaba vinculado a lo que una portera denominó "esta escuela se viene abajo"-aludiendo a lo edilicio como a aspectos del funcionamiento de la institución. Esto era también un problema vivido por varias maestras. Una de ellas nos contó que, hacia fin de año, había pedido una reunión de personal para tratar temas institucionales, porque las relaciones entre las mismas docentes eran tensas.

Otro modo de manifestar el malestar vivido en la escuela estaba vinculado a la historia. Dos de las porteras, quienes trabajan en la escuela desde su fundación y viven también muy cerca, en diferentes oportunidades se refirieron con orgullo a otros momentos de la escuela en los que destacaban la presencia de directoras, entre otras razones, por su capacidad de gestionar. En particular era recordada la directora anterior que se había jubilado y residía a pocas cuadras de la escuela. La directora varias veces nos manifestó que a ella y a la vicedirectora "las tapaban las tareas burocráticas, el papelerío", que terminaba siendo "una gerenta". Como parte de su presentación, contó que aún estaba conociendo el lugar y a la gente, y que el hecho de ser nueva en el lugar no le jugaba a favor. El clima de malestar que se vivía en esta escuela podía ser reconocido por la mayoría de los actores, en ocasiones con menos claridad, en otros momentos a través de situaciones que lo ponían en evidencia y volvían notorias la tensiones internas que se generaban a partir de las disputas por la toma de decisiones y el control de las actividades de quienes allí trabajaban. Fue tal vez esta percepción, especialmente palpable en períodos en que no se dictaban clases por medidas de fuerza, por problemas edilicios y/o falta de servicios, la que nos planteó algunos de los interrogantes sobre los que desarrollamos este trabajo.

\section{Algunas consideraciones metodológicas}

El conjunto de datos con los que trabajamos para construir el argumento de esta ponencia han sido obtenidos durante el desarrollo de una investigación etnográfica en curso denominada "La escuela y las infancias: otras dimensiones de lo político. Un estudio etnográfico en escuelas primarias de la ciudad de Neuquén", cuyo trabajo de campo se realiza desde el mes de febrero de 2010. Las evidencias que sustentan nuestro argumento están organizadas en tres escenas que condensan entramados centrales de las cuestiones que ponemos en discusión, relatadas en la próxima sección.

El trabajo de campo desarrollado hasta la actualidad, consistió en una progresiva integración con el entorno social del lugar seleccionado, a través de la participación personal de los cinco investigadores que conforman el equipo con el que trabajamos las autoras de esta ponencia. Si bien ninguno de los 
investigadores reside en el lugar, la proximidad ha permitido estar ahí de manera bastante asidua incluyendo los días laborales y los fines de semana en horarios diversos. De esa manera, cada uno de los/as investigadores/as a través de su participación personal, fue tejiendo lazos de familiaridad y confianza con diferentes pobladores o trabajadores. En términos generales el trabajo de campo incluyó observación participante y conversaciones con mayor y menor grado de formalidad en distintos lugares e instituciones - dos escuelas, un comedor, casas de familia, comisión vecinal, comisaría, cancha de fútbol, feria, huerta comunitaria, calles y esquinas, entre otros -, con hombres y mujeres, niños y niñas que residen en el lugar, con mujeres y hombres que trabajan en alguna de las instituciones, pero no residen. Implicó también, con el mismo grado de importancia, la continua escritura de las crónicas de nuestros recorridos y encuentros etnográficos - apoyada con fotos y grabaciones - para representar, al menos en parte, $y$ en sus propios términos nuestras vivencias compartidas y reconstruirlas como experiencias.

Para el caso de esta ponencia hemos seleccionado especialmente el conjunto de notas y registros de campo relacionados con la vida cotidiana de una de las escuelas del barrio. Éstos no se reducen a lo que hicimos en la escuela y a los vínculos que allí construimos. Los distintos eventos públicos en los que participamos y las personas con las que compartimos encuentros nos permitieron comprender que la relación entre los porteros y porteras no pueden ser pensada sólo al interior de las escuelas. Esto hizo que acompañemos actividades gremiales (movilizaciones, asambleas, reuniones realizadas en la calle y en otros espacios), conversemos con gente activa de la comisión vecinal, de otras escuelas, con madres y chicos, con policías, sobre esta relación entre problemas edilicios, porteros/as y vida cotidiana escolar. Nuestro acercamiento a los policías fue inducido por docentes y directoras de las escuelas quienes nos contaron que trabajan de manera conjunta en cuestiones vinculadas a la "contención social" de familias y niños. Una primera ponencia en la que abordamos un aspecto de esta relación fue presentada a mediados de 2010 (Pujó, Fernández y Jaramillo, 2010). Este trabajo fue leído por docentes y porteros de la escuela 1 y los comentarios enriquecieron la discusión y aportaron no solo informaciones sino fundamentalmente reflexiones en el plano de lo teórico relativas, por ejemplo, a la noción de trabajo y trabajador. Sobre la base de estas reflexiones compartidas con los trabajadores y pobladores del lugar -en un proceso de interacción, diferenciación y reciprocidad entre nuestra reflexividad y la de los actores (Guber; 2001, p. 53) continuamos la exploración de la temática y en esta búsqueda emergió la política educativa como instigadora de interrogantes. 


\section{"En esta escuela... mandan los porteros"}

La frase con la que titulamos este apartado fue expresada por una vecina que envía sus hijos a la escuela de al lado, durante el primer mes de clases del año 2011 en que la escuela 1 no iniciaba su ciclo lectivo por problemas edilicios. Según ella, una parte de los problemas que tenía esta escuela para regularizar su funcionamiento tenía que ver con el peso que ejercían los porteros. Esta expresión no refleja ni representa las relaciones laborales y jerárquicas tal como se dan en la escuela. Nos pareció relevante porque, por un lado, ya la habíamos escuchado de boca de otras vecinas, de porteros de otra escuela e incluso de personas de la misma escuela. Por otro, era reveladora del lugar y del rol importante que tenían los porteros y las porteras. Y también porque en su enunciación acusadora, expresaba un conflicto en términos de mando y de poder.

Nuestro primer encuentro con las personas que trabajan en la escuela 1 fue durante las semanas posteriores a la fecha fijada por el Consejo Provincial de Educación, CPE, para el comienzo del ciclo lectivo 2010. En la escuela 1, de igual manera que en muchas otras de la ciudad, no había comenzado el dictado de clases. El día que llegamos tuvo una particularidad: no había paro de los/ as docentes de la Asociación de Trabajadores de la Educación del Neuquén, ATEN (que mantenían un plan de lucha progresivo), pero sí de los/as porteros/ as de esta escuela, todo/as afiliados a la Asociación de trabajadores del Estado, ATE. Ante nuestras preguntas de recién llegados, la directora nos explicó: "Acá no es que nos falte agua" [como sucedía en otros establecimientos], sino que "están de paro los porteros". Una maestra dijo que la otra escuela había comenzado con sus clases "porque allí los porteros no realizan la medida". Y otra maestra afirmó: "nosotros no comenzamos por paro de porteros, la otra escuela empezó porque en esa escuela los porteros trabajan". Posteriormente, en varias oportunidades, las porteras y los porteros explicaron que el personal de servicio de la escuela 2, estaba afiliado a otro gremio -Unión de personal civil de la Nación, UPCN- y que sólo suspendían las clases cuando las y los docentes hacían paro, como una forma de "acompañar su medida". A medida que transcurrió el tiempo y conocimos más, fuimos entendiendo algunos vínculos entre las medidas de fuerza que tomaba ATEN y ATE y UPCN para el sector educación y-como sucede en todas las provincias de nuestro país- la política en sus niveles municipal, provincial y nacional. Sin embargo, estos vínculos no explican por si mismos lo que sucede en cada escuela singular, ya que también en cada una de estas instituciones las relaciones políticas adquieren características particulares referidas a las luchas por el control de las mismas. La escena que relatamos a continuación da cuenta de esta trama compleja de vínculos.

El día jueves 5 de abril de 2010 llegamos a la escuela 1 por la mañana temprano. ATE había decidido medidas de fuerza en el sector educación y 
salud para ese día. Los porteros y porteras de esta escuela estaban presentes pero con retención de servicios. Cuando nos encontramos con ello/as nos comentaron que estaban enojados porque un grupo de mujeres, madres de estudiantes de la Escuela Provincial de Enseñanza Técnica (EPET) - ubicada en el mismo barrio -, estaban limpiando la escuela. Para ello/as el accionar de estas mujeres "boicoteaba" las medidas de fuerza de ATE. Además, conocían a esas mujeres, vecinas del barrio y sabían que eran "punteras" de un sector del partido gobernante, Movimiento Popular Neuquino, MPN. Por eso aseguraban que su intención no era que la escuela estuviera limpia, sino "romper" la medida de fuerza de ATE. Como nosotras sabíamos las diferencias entre ATE y el MPN, entendimos sin necesidad de mucha explicación de qué se trataba. Mientras conversábamos con ellos/as un mensaje de texto, vía teléfono celular, los/as convocó a asistir a la EPET para acompañar la presencia del delegado gremial de ATE que se encontraba allí. Nos invitaron a ir con ellos/as hasta el lugar y por supuesto, los acompañamos. Al llegar vimos un grupo de alrededor de 50 personas, dos policías parados en la calle, un tanto separados del grupo más compacto que está frente al portón cerrado de rejas, por donde se ingresa al colegio. Detrás del portón algunas mujeres baldeaban el piso del patio de la escuela y el agua con tierra corría hacia la calle. Entre el grupo de personas que estaban afuera se distinguían dos hombres dialogando y dando explicaciones al grupo. Una portera de la escuela nos comentó "ese que está hablando es el director y el otro grandote que está con él es el vice". El director es un hombre joven que se dirige con seguridad a todo el grupo. No vacila en contestar. En su discurso explica "queremos tener un contacto con los pibes sino esto se va al carajo". El otro hombre estaba vestido con ropa de trabajo color beige y entre sus argumentos decía: "ustedes ¿se van a hacer responsables de lo que hagan las madres?", "¡nos están usurpando nuestro lugar de trabajo!" La portera de la escuela 1 nos comenta en voz baja: "ese es el delegado de ATE". Las otras personas presentes -porteros y porteras de esa escuela y escuelas aledañas, según nos informaron- por momentos confirmaban o abucheaban con expresiones, cánticos y dialogando entre sí. Entre las muchas y variadas expresiones escuchamos: "esta es una medida de los porteros", "yo también soy madre y tengo mi hijo acá", "ya le dije a mi hijo, basta de estar jugando por ahí, ponete a estudiar", "yo estoy de los dos lados, qué le parece". También presenciaban la situación algunos adolescentes que daban vueltas por alrededor.

Alli escuchamos al delegado argumentar que "nos están usurpando nuestro lugar de trabajo", haciendo referencia a las madres que en ese momento estaban limpiando. El director le explicaba que la escuela había sido terminada por una ocupación del edificio y sucesivas medidas de reclamo por parte de las familias y por esa razón, "no puedo negarles que entren ahora". Luego expresó que no quería que las/os chicas/os se vayan de la escuela, y que al día siguiente no había paro docente y debía haber clases normales: 
"No queremos la escuela vacía (...) las clases estaban suspendidas porque la escuela estaba sucia, pero si la escuela está limpia, está en condiciones para dar clases, desaparece la condición de suspensión" (Registro de campo: Director de la EPET, 05/04/2010)

Por su parte, el delegado de los porteros replicó:

"Si esto se da así nosotros vamos a dejar por sentado, mediante un acta, que los compañeros en estas condiciones no pueden estar en la escuela, porque desde temprano los padres están provocándolos. Estas no son condiciones normales, lo normal es que sean los auxiliares los que limpien la escuela. Cuando los docentes hacen paro no vienen otros a dar sus clases" (Registro de campo: Delegado de ATE, 05/04/2010).

Era claro para todos que el delegado de ATE se dirigía al director en su condición de tal, pero también como afiliado a ATEN. Mientras participábamos de esta discusión se escuchaban comentarios y rumores entre las personas que no lograron interrumpir la discusión entre el director y el delegado de ATE. Pero en un momento, una de las madres tiró un balde de agua hacia fuera y grito: "córranse porque es agua con lavandina". Uno de los porteros con tono de enojo respondió: "señora, déjese de joder" e inmediatamente la madre contestó, "no estoy jodiendo, estoy limpiando". La sentencia del portero fue mayor: "No. Está jodiendo, ¿no ve que estamos en una reunión?". También se escuchó a otra portera: "son punteras, mandadas por el gobierno", "quieren dividirnos, quebrar la lucha". Luego los periodistas presentes entrevistaron al director de la EPET, mientras el delegado de ATE junto a los/as porteros/ as comenzaron a labrar el acta de los sucesos. Nosotras y los porteros de la escuela 1 regresamos a la escuela.

Esta situación, en un principio, nos permitió advertir la centralidad que tenía la limpieza de los edificios escolares en el contexto de conflictividad que marcaba el no inicio de clases, y cómo a través de ello lo que se estaba discutiendo iba más allá del cuidado de las instalaciones. Lo que aquí se puso en cuestión no era sólo quién debe o no limpiar la escuela, sino el propio control del colegio; y de esa disputa formaron parte el director, el delegado de ATE, porteros/as de esa escuela y de otras, y madres de alumno/as del colegio. Quienes discuten y pugnan por definir si en esa escuela hay clases o no, lo hacen desempeñando más de un rol y, a través de esos roles, ponen en juego los diversos grupos políticos en tensión. Cuando el director habla lo hace como director y afiliado a ATEN; las madres, como madres y mujeres del MPN; y los/as auxiliares como porteros/as y afiliados a ATE. El forcejeo para decidir si en este colegio comienzan o no las clases, se produce entre sujetos que exhiben autoridad por los lugares que ocupan como sindicalistas, trabajadores, punteros políticos y familiares. $Y$ en ese forcejeo, el grupo de los porteros/as, además de exhibir argumentos discursivos, pone en escena 
su fuerza a través de la presencia de un dirigente reconocido de ATE y de las personas afiliadas, como los porteros de la escuela 1. Por su parte el director se establece como autoridad escolar y pedagógica preocupado por el inicio de clases, pero su presencia tiene cierta debilidad en tanto no exhibe respaldo de pares -otros directores- ni de docentes, alumnos/as y padres/madres del establecimiento. $Y$ las pocas madres presentes detrás del portón cerrado no argumentan, sólo arremeten con el agua y el balde y, en el breve diálogo que entablan con el sindicalista, confirman ante ese público, que no están como madres, sino como punteras. La entrada de ese colegio durante esas horas de la mañana se convirtió en escenario de disputas políticas que atravesaban la vida de la escuela y se extendían mucho más allá de ella.

Otras situaciones similares, a las que accedimos por los medios de comunicación, se dieron en otras escuelas y en otros puntos de la provincia, reflejando la tensión pública que generaban las medidas de fuerza y los enfrentamientos políticos a los que dio lugar.

En el mes de mayo finalizaron las medidas de fuerza de las/os porteras/ os afiliados a ATE, y de los/as docentes de ATEN. Si bien ambos sectores percibieron aumentos, estos no fueron significados como importantes y el descontento y cansancio pos huelga fue algo mencionado por varios/as docentes y porteros/as.

En el mes de septiembre las/os porteras/os nucleados en ATE volvieron a realizar medidas de fuerza, y los de la escuela 1 las llevaron adelante. En este contexto una nueva situación generó tensiones en la vida de la escuela: la directora y vice tomaron los artículos de limpieza y comenzaron a limpiar la escuela para que las clases pudieran continuar a pesar de las medidas de fuerza. Ese día no habíamos ido, pero los relatos posteriores fueron lo suficientemente elocuentes como para percibir la importancia que tuvo para todos esa situación. Una maestra nos contó su visión sobre el suceso:

"¿Qué hacemos las maestras del turno tarde?, porque las aulas estaban todas sucias por los de turno mañana, porque a la mañana hicieron paro y a la tarde había uno solo (...) Ver los chicos sentados en la galería y la directora y la vice pasando el lampazo y limpiando las aulas... yo dije, ¿Qué estoy haciendo acá?, ¿Qué estoy enseñando? (...) yo quiero enseñar a mis alumnos que el día de mañana cuando vaya y se queje porque hay una injusticia, va a haber alguien que le va a hacer las cosas para que no se enoje? Esa lectura hice yo. ¡Y peor! Cuando se involucró a dos o tres alumnos adentro del aula a limpiar las mesas, cuando al alumno se lo manda a estudiar y no a limpiar. Entonces, ¿los derechos hasta dónde? Derechos a estudiar ¿y? ¿Lo mandas a limpiar!!? Y...pero tenemos que colaborar. ¡Pará!, colaboremos cuando hablamos de colaboración no cuando hay una medida de fuerza por un reclamo salarial que, además, es justo" (Entrevista con docente, 03/09/2010). 
Otra maestra también nos relató el hecho y agregó "nosotras ahí paradas en las puertas de las aulas mirando, no podíamos creer que hayan caído tan bajo...". Cuando preguntamos a los porteros sobre la situación, una de ellas dijo sin dar demasiados detalles: "hablamos con la directora y le aclaramos las cosas, hay que ponerse firme acá. Después no volvió a pasar". La directora y la vicedirectora no nos comentaron el tema, nosotras advertimos que las tensionaba. Evidentemente, no habíamos logrado suficiente confianza para hablar de una acción que tal como había sido vivida, denostaba de alguna manera su lugar como autoridades de la escuela. Durante esos días la misma maestra de quien recuperamos el primer relato, intentando explicar-se lo que había sucedido, nos dijo: "parece más fácil depositar el problema en lo que se ve que en lo que no se ve. El conflicto entre lo sucio y lo limpio es sólo un grano que estalló". Ese "grano" aludía a las tensiones contenidas en las relaciones entre quienes trabajaban en la escuela y se expresaron a través de la limpieza.

Nuevamente en el centro de la escena estuvo la disputa por el control de la escuela. Pero en este caso se produjo cuando quienes detentaban la autoridad máxima de la escuela por su cargo de directivas, pusieron en sus manos la tarea de barrer. Esta acción, quizás, en otro contexto podría haber sido interpretada como un modo de imponer autoridad. Pero, como ya sabemos, las acciones adquieren significado en la relación con los otros, donde los contextos también aportan su carga de sentidos. En una situación de descontento del grupo de portero/s, de compromiso con la medida de fuerza del sindicato y de cierta debilidad por parte de la autoridad de la escuela, entre otros factores, ver a los directivos haciendo lo que les corresponde a los porteros fue vivido como disputa por el mando. Recuperando las palabras de la maestra, lo que "estalló" tanto aquí como en otras situaciones fue la autoridad, quién toma las decisiones y manda en esta escuela, lo cual es, concretamente, parte de la política educativa.

El año escolar 2011 parecía presentarse de otro modo. Durante los últimos meses del año anterior el gremio de las/os docentes, ATEN, había acordado un aumento salarial que, aunque considerado insuficiente por muchos/as, definió un inicio de ciclo lectivo 2011 sin paro. Después de siete años consecutivos, se esperaba que las clases en Neuquén comenzaran de acuerdo al calendario académico oficial: el 28 de febrero. Sin embargo, una gran cantidad de escuelas no tenían sus edificios en condiciones de comenzar las clases. Entre ellas, la escuela 1. Entre los problemas más importantes estaban el deterioro de los tanques agua y de las puertas de las aulas. Los tanques tenían sedimentos y suciedad y, por sus años de uso, ya no podían limpiarse. Era imprescindible cambiarlos y por eso quienes habían ido a realizar la limpieza -enviados por el CPE- los vaciaron y la escuela quedó sin agua. Tampoco había puertas en las aulas, dado que las paredes de durlock con el tiempo ceden y las aberturas necesitan arreglos. 
Una mañana de esas largas jornadas sin clases llegamos a la escuela. En la vereda nos cruzamos con dos porteras y una de ellas nos sorprendió con su comentario: -"Estamos sin clases, pero ahora no es por el paro de los porteros". Esta acotación llamó nuestra atención en el momento pero luego pudimos comprender mejor su sentido. Efectivamente el sindicato ATE estaba con medidas de fuerza y los porteros las cumplían pero no de manera rígida. Ellos se habían sentido cuestionados el año anterior y, según nos explicó una de las porteras, no querían quedar como los responsables del no inicio de clases. Pretendían que fuera visible que lo que impedía dictar clases era la situación edilicia. Más aún, en varias oportunidades nos hicieron ver que en parte esa escuela no se arreglaba, porque la dirección no ejercía presión suficiente en el CPE. También entre las maestras se percibía como escasa y débil la presión para lograr los arreglos. Entonces los responsables del no inicio eran, en primer lugar, las autoridades educativas que estaban denunciadas por el sindicato docente y ATE, por haber distraído presupuesto. Y en segundo lugar, el personal directivo que no realizaba la presión suficiente para que el reclamo de esta escuela fuera atendido.

El tema sobre el no inicio de las clases de esta escuela también se comentaba afuera. En una conversación con porteros/as de la escuela de al lado, afiliados a UPCN, contaron que ellos no tenían "esos problemas" y que "cuando hay algún problema nosotros tratamos de solucionarlo. No esperamos que vengan del consejo... a veces vienen y hacen cagadas, o lo arreglan peor". Sin embargo, unas semanas después, nos encontramos con la directora de esa escuela que estaba presionando a las autoridades del CPE porque no tenía la calefacción en condiciones y amenazaba con suspender las clases. Lo cual indica que también tenían problemas que no podían ser solucionados por los porteros Al mismo tiempo, entendimos que esa expresión "no tenemos esos problemas", iba más allá de lo material.

En otra ocasión un dirigente de la Comisión Vecinal directamente acusó a los porteros de la escuela 1 como causantes de algunos de los problemas edilicios. Si bien su acusación no nos resultó creíble, nos ayudó a entender el sentido de la expresión "no hay clases, pero no es por paro de los porteros".

Un mediodía nos quedamos conversando con un grupo de cinco porteros/ as en la puerta de la escuela. Nos llamó la atención que estuvieran todos/as afuera y ellos/as nos explicaron que estaban esperando a la directora que llegaba de un momento a otro. Viene con pintura!- dijo en tono de sorna una de las porteras. Y otra agregó: "Ahora quiere que pintemos la escuela y yo ahora sí que no voy a hacer nada. Nosotros antes hacíamos", otra de las porteras reforzó: "nosotros hacíamos todo acá, pero jlas puteadas de los padres! No te reconocen nada...". Con claridad afirmaron que cuando llegara la directora le iban a comunicar que ellos no iban a pintar. 
Al día siguiente al entrar a la escuela sentimos mucho olor a pintura. Un portero estaba terminando de pintar una de las aulas. Entre el despliegue de hojas de diario y pintura le preguntamos por qué habían cambiado de opinión. Y nos explicó "pintamos por los chicos". La conflictividad alrededor de lo edilicio nuevamente era el punto de inflexión en esta escuela. Y los porteros a través de ello exhibían su posición dentro de la escuela, demostrando su injerencia, en este caso no haciendo el paro y pintando, tarea que no les corresponde hacer. Al conversar con la directora sobre lo sucedido, en torno a la pintura, con una metáfora nos explicó su visión de la situación: "mirá, esto es como un matrimonio, tenés que hacerles creer que son ellos los que mandan, pero la que manda, de verdad, es una". Nuevamente en la escuela 1 se hacía visible la disputa sobre la influencia dentro de la escuela, con una puesta en cuestión, relativamente continua, sobre quién manda. La pugna por el control que ejercían los/as porteros/as a través de lo edilicio ante a una dirección debilitada, ponía sobre el tapete su protagonismo en la toma de las decisiones, interviniendo en la política educativa y su materialización en el cotidiano escolar.

\section{Políticas y desigualdad: cuando "no ponen la cara"}

En sus análisis de la relación entre políticas educacionales y desigualdades, Miguel Arroyo (2010) afirma de manera muy acertada, que predominan formas de pensar al Estado como centro y a las desigualdades sin sujetos. En su crítica a este modo de pensar, argumenta que los sujetos y colectivos son considerados simplemente objeto de las intervenciones políticas del Estado, precisamente porque se los ignora como sujetos, individuos y colectivos y se los produce como desiguales. De ahí que la relación privilegiada en estos modos de pensamiento y comportamiento es Estado, políticas e instituciones públicas, en abstracto. "El único sujeto de acción será el Estado, sus políticas, sus instituciones y sus gestores que se proponen resolver desigualdades (...) Consecuentemente, la historia de los procesos de producirlos como desiguales es ignorada y las políticas muestran el protagonismo o la ausencia del Estado" (Arroyo, 2010: 1386). Aunque tal vez no exactamente en los términos de este artículo de Arroyo, la temática que exponemos en este trabajo también ingresa en las relaciones entre políticas educativas y desigualdades, ya que las condiciones y recursos materiales de las escuelas estatales también forman parte de la producción de colectivos desiguales. De hecho las escuelas de la ciudad de Neuquén que no pudieron comenzar el ciclo lectivo del año 2011 por problemas edilicios y de servicios -agua, luz, gas-, estaban situadas en su mayoría, en la zona oeste. Y ya avanzado el ciclo, son las mismas escuelas que deben suspender sus clases asiduamente por problemas edilicios y de falta de servicios. Por eso, para entender las políticas edilicias en el sector educación, era imprescindible poner el foco en los sujetos y colectivos que intervienen y en las relaciones sociales implicadas en la implementación de esas políticas. 
Esto no implica dejar fuera del análisis al Estado. Muy por el contrario, nos permitió evitar análisis inconducentes de políticas en términos dicotómicos: protagonismo o ausencia del Estado.

A través de nuestras descripciones mostramos que en las confrontaciones suscitadas por problemas edilicios emergen otras disputas y diferencias, lo cual no llama tanto la atención. En un artículo anterior, en el que analizamos las formas de mantención, refacción, cuidado y decoración de los edificios escolares, señalábamos que, con relación a problemas edilicios, los Estados nacional y provinciales actuaban desde hacía tres décadas, respondiendo a pedidos, protestas y demandas en las que participaban docentes, auxiliares, padres y familiares. Indicábamos también que esas demandas tenían como objetivo presionar y exigir a las autoridades la atención de problemas puntuales para el funcionamiento de las escuelas. Y que al ser movilizaciones que giraban en torno a escuelas concretas de zonas determinadas, solían adquirir una fuerte capacidad de cuestionamiento político (Milstein y Mendes, 2005, p. 21). Lo llamativo en este estudio que estamos desarrollando es que la cara del Estado provincial se ha desdibujado aun más. No están ausentes pero no son palpables. No solamente porque "no están ahí dando la cara"-como reiteradamente decían directivos y docentes-. Sino también porque esas demandas se desplazan, de manera relativamente rápida, hacia otros conflictos políticos en los que todos saben que está presente y actuando el Estado. Lo que confunde es que no lo hace como actor decisivo en la implementación de las políticas edilicias. Lejos de esto, "los esfuerzos estatales están más vinculados a producir una suerte de desplazamiento hacia formas de gobernabilidad informal, mediante contactos informales y gestiones personales, [de] cada escuela singular y concreta" (Milstein, 2009:176). Produce de este modo un desorden en las relaciones entre autoridades estatales y escuelas; una suerte de descomposición de las vías jerárquicas y administrativas que estimulan las disputas internas en las escuelas, entre sindicados y demás.

\section{A modo de cierre}

Indudablemente, existe una historia del lugar que han ido ocupando los porteros y las porteras en las relaciones que hacen posible la implementación de las políticas educativas destinadas a la cuestión edilicia que aun no hemos estudiado. Sin embargo como afirma Arroyo, cuando otros actores políticos organizados entran en escena, existe una presión para que las políticas sean repensadas y resulta difícil seguir viendo al Estado como solución, como único actor (Arroyo, 2010, p. 1411). Por eso, nos animamos a afirmar que la reestructuración de las escuelas primarias a partir de la década del 90 dio lugar a instalar nuevos modos de hacer política escolar y entendemos que los resultados de nuestra investigación aportarán a iluminar aspecto en este sentido. 


\section{Referencias bibliográficas}

- Arroyo, M. (2010). Políticas educacionais e desigualdades: á procura de novos significados Educacão e Sociedade, Campinas, v. 31, n. 113, p. 1381-1416, octubre-diciembre. 2010 Disponible en http://www.cedes.unicamp.br Acceso 2/2/ 201.

- Guber, R. (2009). El salvaje metropolitano. Reconstrucción del conocimiento social en el trabajo de campo. Buenos Aires: Paidós.

- Milstein, D. (2009). La nación en la escuela. Viejas y nuevas tensiones políticas. Buenos Aires: Miño y Dávila.

- Milstein, D. y Mendes, H. (2005). La escuela y la ciudad: estética y ética en el período de la conformación del Estado en Argentina en revista Inter-ação Faculdade de Educação, Universidade Federal de Goiás v.29, n. ${ }^{01}$, jan./jun. de 2004. (pp 11-24).

- Pujó, M. T., Fernández, S. y Jaramillo, J. (2010). Disputas políticas en la vida cotidiana escolar: Lo "limpio" y lo "sucio" como lucha simbólica en una escuela neuquina. Ponencia presentada en Encuentro de Jóvenes Investigadores / 10, Santiago del Estero. 